Article

\title{
Unselective Transport of Phytopathogenic Fusarium Fungi from Litter and Soil by Ground-Dwelling Arthropods Links Semi-Natural and Agricultural Habitats
}

\author{
Nadja Heitmann ${ }^{1,2, *(\mathbb{D},}$, Michael Glemnitz ${ }^{1}$ D, Klaus Birkhofer $^{2}$ and Marina E. H. Müller ${ }^{1}$ \\ 1 Leibniz Centre for Agricultural Landscape Research (ZALF), Eberswalder Str. 84, \\ 15374 Müncheberg, Germany; mglemnitz@zalf.de (M.G.); mmueller@zalf.de (M.E.H.M.) \\ 2 Department of Ecology, Faculty of Environment and Natural Sciences, Brandenburg University of Technology, \\ Cottbus-Senftenberg, Konrad-Wachsmann-Allee 6, 03046 Cottbus, Germany; klaus.birkhofer@b-tu.de \\ * Correspondence: nadja.heitmann@zalf.de or nadja_heitmann@hotmail.de
}

Citation: Heitmann, N.; Glemnitz, M.; Birkhofer, K.; Müller, M.E.H.

Unselective Transport of

Phytopathogenic Fusarium Fungi from Litter and Soil by

Ground-Dwelling Arthropods Links Semi-Natural and Agricultural

Habitats. Microorganisms 2022, 10,

335. https://doi.org/10.3390/

microorganisms10020335

Academic Editor: Michael J.

Bidochka

Received: 29 December 2021

Accepted: 29 January 2022

Published: 1 February 2022

Publisher's Note: MDPI stays neutral with regard to jurisdictional claims in published maps and institutional affiliations.

Copyright: (C) 2022 by the authors. Licensee MDPI, Basel, Switzerland. This article is an open access article distributed under the terms and conditions of the Creative Commons Attribution (CC BY) license (https:// creativecommons.org/licenses/by/ $4.0 /)$.

\begin{abstract}
The dispersal of propagules, such as fungal spores or seeds by actively moving animals, connects and shapes communities. The dispersal of plant pathogens by arthropods might be a crucial mechanism in the spread of several crop diseases. Ground-dwelling arthropods are potential linkers between fungal communities in semi-natural and agricultural habitats by transporting propagules of Fusarium fungi. We compared the Fusarium communities on the body surface of ground-dwelling arthropods with litter in semi-natural and soil in agricultural habitats with a focus on the Fusarium community. We found three relatively distinct Fusarium communities with moderate overlap. We detected a higher richness of Fusarium species on the body surface of arthropods compared to litter and soil communities. The results suggest that the Fusarium community on the body surface of arthropods relates to the composition observed in litter and soil with limited filtering mechanisms between communities. Ground-dwelling arthropods are relevant agents for the distribution of Fusarium and therefore link fungal communities in adjacent habitats.
\end{abstract}

Keywords: insect-vector; ground-dwelling arthropods; Fusarium; phytopathogenic fungi; mycobiota; wheat; linkage; community

\section{Introduction}

The dispersal of propagules, such as spores or seeds by actively moving vertebrates or invertebrates, shapes ecosystems and communities in different ways, which is defined by the mobile link concept [1]. By moving actively within semi-natural habitats and through spillover into adjacent arable habitats, animals can introduce species or genes. Such passive dispersal links fungal communities but may also promote the spread of organisms that provide ecosystem disservices, such as phytopathogenic fungi. The dispersal of propagules from plant pathogens by arthropods might be a crucial mechanism for the spread of several crop diseases. It can enhance the spread of the pathogen and the disease development, shown for the kernel rot of maize (Zea mays L.) or Fusarium head blight (FHB) in wheat (Triticum aestivum L.), or the laurel wilt disease of avocados (Persea americana Mill.) [2-4].

One of the major pathogens in wheat production is fungi of the genus Fusarium. Nineteen Fusarium (F.) species are involved in the crop disease Fusarium Head Blight, $F$. culmorum (W.G. Smith) Saccardo, and F. graminearum Schwabe, which are among the most pathogenic species [5]. A reduced wheat grain size and quality as well as the production of mycotoxins are the results of this disease [6]. The composition of Fusarium communities and the severity of the disease in the crop are both affected by the fungal community in primary inoculum, which can arise from crop or weed plants, plant residuals, or soil $[7,8]$. The Fusarium community associated with weeds and their litter within crop fields and surrounding field margins is very diverse and consists of multiple Fusarium species such as 
F. graminearum, F. verticillioides (Saccardo) Nirenberg, F. oxysporum Schlechtendahl emend. Snyder \& Hansen, F. culmorum, or F. subglutinans (Wollenweber \& Reinking) Nelson, Toussoun \& Marasas [8,9]. Weed species, especially grasses, can act as alternative hosts for Fusarium species and may harbor pathogenic fungal strains for cereal crops [10].

Ground-dwelling arthropods contact with fungal inoculum while moving through plant material or soil that is colonized by fungi [11,12]. Thereby, fungal propagules can attach to the body surface of arthropods (ectozoochory) [13]. Furthermore, many grounddwelling arthropods such as carabid beetles or woodlice may hibernate in soil or seek shelter in small crevices or plant litter [14,15]. Fungal propagules can also adhere to the body surface while arthropods feed on colonized plant or soil material or on fungal mycelia or spores (fungivory), which is typical for many springtail species [16]. Numerous arthropod species of different taxa and trophic groups, such as herbivores, fungivores as well as predators are potential carriers of phytopathogenic fungal propagules, shown for ants, millipedes, and spiders [17]. Previous studies documented frequent external and internal transportation of multiple fungal taxa, including several species of the genera Fusarium, by ground-dwelling carabid beetles [18]. In general, fungal propagules can easily adhere to micro-structures such as bristles, hairs, and spines on the body surface of arthropods or the joints and mouthparts [19].

Ground-dwelling arthropods are potential linkers between semi-natural and agricultural habitats by transporting propagules of Fusarium fungi. Due to their prevalent movement type and distinct ecology, they are very likely to get in contact with primary inoculum and propagules of Fusarium spp. when moving on the ground or feeding on weeds and their residuals. Ground-dwelling arthropods are a very abundant and diverse group, and individuals of many species move frequently between semi-natural and agricultural habitats [20]. Their role in the dispersal of Fusarium across habitat borders is unknown.

This study compares the total fungal load and Fusarium communities on the body surface of ground-dwelling arthropods, the litter layer of semi-natural habitats, and the soil of agricultural habitats. The study was conducted around kettle holes in agricultural landscapes, as these habitats provide an abundance of host plants in which residuals (litter) may act as a source for phytopathogenic fungi such as Fusarium. In agricultural landscapes, kettle holes act as important conservation hot spots for many arthropod taxa such as carabid beetles or spiders [21,22].

Hypothesis 1. The total fungi and Fusarium load of the body surface of ground-dwelling arthropods is determined by the total fungal and Fusarium abundance in soil (for arable fields) or litter (for semi-natural habitats).

Hypothesis 2. The species richness of Fusarium communities on the body surface of grounddwelling arthropod is higher than in the soil or litter since arthropods move in both habitats.

Hypothesis 3. The composition of Fusarium species in terms of relative abundances on the body surface of ground-dwelling arthropods is similar to that in soil (for arable fields) or litter (for semi-natural habitats).

\section{Materials and Methods}

\subsection{Study Site}

The study site is located approx. $90 \mathrm{~km}$ north of Berlin in the Uckermark region in the Federal State of Brandenburg, Germany, in the Lowlands in North Germany, (GPS coordinates of the study area: between Fürstenwerder (53 $\left.23^{\prime} 19^{\prime \prime} \mathrm{N} 13^{\circ} 35^{\prime} 2^{\prime \prime} \mathrm{E}\right)$ and Prenzlau $\left(53^{\circ} 19^{\prime} 2^{\prime \prime} \mathrm{N} 13^{\circ} 51^{\prime} 48^{\prime \prime} \mathrm{E}\right)$ ). The agricultural landscape laboratory Quillow (AgroScapeLab) of the Leibniz Centre for Agricultural Landscape Research [23], in which this study was carried out, is located within this region. The subcontinental climate in this area shows a long-term mean annual temperature of $8.6^{\circ} \mathrm{C}$ and average long-term annual precipitation of $564 \mathrm{~mm}$ (ZALF field station, Dedelow). The area represents typical landscapes in Central 
continental Europe that are formed by glaciations of the Pleistocene and post-glacial processes. Kettle holes, which are small water bodies surrounded by semi-natural vegetation margins, were created by Pleistocene processes in a high number [24].

\subsection{Sampling Design}

We analyzed the fungal community associated with ground-dwelling arthropods, soil, and litter at seven kettle holes surrounded by winter wheat fields. Kettle holes were selected according to their permanent presence of water during the year, size of their water body (min. $25 \mathrm{~m}^{2}$ ), their distances (at least $50 \mathrm{~m}$ ) to field borders, roads, or other landscape elements, and the vegetation of their margins (dominated by grasses). Each kettle hole was sampled at three replicated sampling points (A, B, and C) that were at least $8 \mathrm{~m}$ apart from each other and $1 \mathrm{~m}$ into the crop field (Figure 1). Sampling points were placed into grassy margins, with at least $10 \mathrm{~m}$ distance to any trees or shrubs.
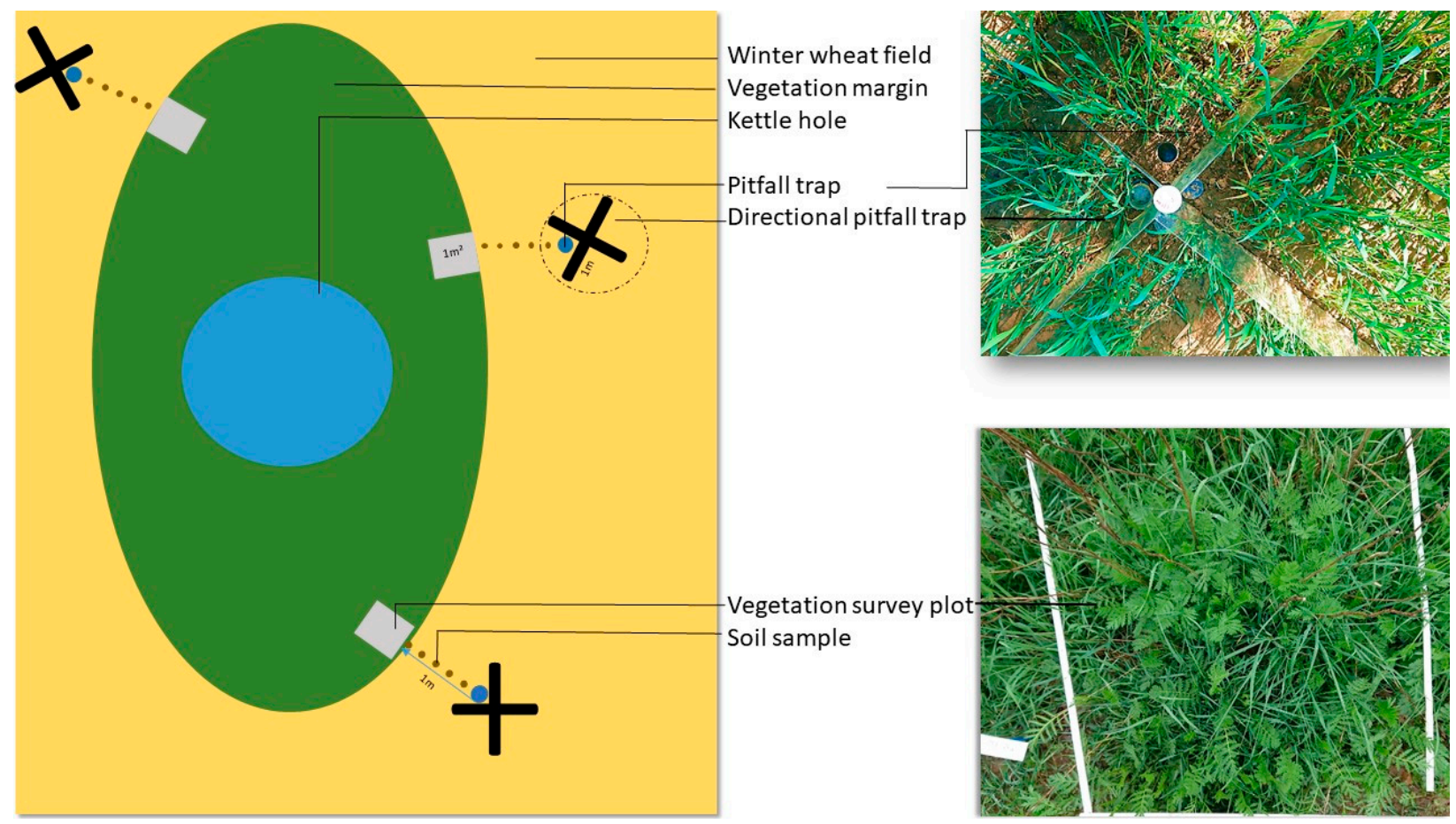

Figure 1. Sample design for the collection of arthropods, litter, and soil samples for the comparison of the associated fungal community. Seven kettle holes were sampled in total.

We collected ground-dwelling arthropods at each sampling point with a system of directional pitfall traps. Two transparent acrylic glass plates $(2 \mathrm{~m} \times 0.25 \mathrm{~m})$ were inserted upright ca. $2 \mathrm{~cm}$ into the ground in a cross-design. The glass plates acted as a barrier to direct arthropods into pitfall traps (glass jars, upper diameter: $6.5 \mathrm{~cm}$ ) that were inserted into the ground at each of the four corners of the directional pitfall trap (Figure 1). For this study, only arthropods that were collected with the pitfall trap facing the edge of the kettle holes were analyzed in order to study beetles that moved from the vegetation of the kettle hole into the crop field. The traps were operated between 25 and 26 May 2020 for $24 \mathrm{~h}$ without any collecting or preservation fluid to avoid the displacement or damage of fungal propagules. All arthropods were sorted individually in $2 \mathrm{~mL}$ Eppendorf tubes after collecting and were stored at $5{ }^{\circ} \mathrm{C}$ in darkness overnight after sampling.

Samples were then analyzed by the microbial culture-dependent method within $24 \mathrm{~h}$ described under paragraph "2.3. Fungal load on the body surface of arthropods and fungal abundances in soil and litter". After the microbial analyses, the arthropods were stored in $70 \%$ ethanol and taxonomically determined following the script of Stresemann [25]. The arthropod taxa and their number of individuals used in the analyses are listed in Table S1. 
The vegetation of the margins surrounding the kettle holes was sampled by establishing $1 \mathrm{~m} \times 1 \mathrm{~m}$ plots at each sampling point beginning at the edge of the crop field (Figure 1). A vegetation survey prior to the arthropod sampling was conducted on the same day. The total surface cover by vegetation $(\%)$ and mean height $(\mathrm{cm})$, the relative cover of grasses (\%), as well as the share of dead plant biomass on total biomass (\%), were visually estimated following the Braun-Blanquet approach (Table S2). Within the $1 \mathrm{~m} \times 1 \mathrm{~m}$ plots, litter samples consisting of circa $100 \mathrm{~g}$ of dead and living plant parts up to a height of $10 \mathrm{~cm}$ were collected on 25 May 2020 based on the previously conducted vegetation survey. Soil samples (circa $100 \mathrm{~g}$ ) were taken at each sampling point on 24 May 2020. The soil of the upper $3 \mathrm{~cm}$ was sampled across lines between the vegetation margin of the kettle hole and the position of the pitfall traps in the winter wheat fields. We assume that fungi in deeper soil layers do not relate to the fungal community on arthropods moving over the soil and would therefore not explain patterns of fungal abundance and Fusarium communities on the arthropods. Five soil samples along every line were mixed into one bulk soil sample at each sampling point. The dry mass of the litter and soil samples was determined by drying a subsample of $5 \mathrm{~g}$ of each sample for $24 \mathrm{~h}$ at $105^{\circ} \mathrm{C}$ for soil samples and $48 \mathrm{~h}$ at $60^{\circ} \mathrm{C}$ for litter samples. The fresh and dry weights of the samples were compared to calculate the dry mass.

\subsection{Fungal Load on the Body Surface of Arthropods and Fungal Abundances in Soil and Litter}

We quantified viable propagules of fungi in general (total fungi) and fungi of the genus Fusarium attached to the body surface of arthropods (exogenous) as well as in the soil and the litter samples. Arthropods were stored for $20 \mathrm{~min}$ at $-20^{\circ} \mathrm{C}$. The $1.1 \mathrm{~mL}$ quarter-strength Ringer's solution with $0.1 \%$ Tween 80 was added to one arthropod per one Eppendorf tube. Arthropod samples were then placed into an over-head shaker for $2 \mathrm{~min}$ at $30 \mathrm{rpm}$ at room temperature to remove fungal propagules from the body surface via a washing process, according to Heitmann et al. 2021 [18]. A subsample of 5-7 g of plant material was selected from each litter sample. The plant material was added to $180 \mathrm{~mL}$ sterile aqua dest and treated for $2 \mathrm{~min}$ in the Stomacher 400 Circulator (Seward Ltd., Thetford, United Kingdom), according to Müller et al. 2018 [26]. Then, $10 \mathrm{~g}$ of the fresh soil samples were immersed in $90 \mathrm{~mL}$ sterile pyrophosphate solution $(0.1 \%$ sodium pyrophosphate $+0.8 \%$ sodium chloride). Five grams of sterilized natural stones (diameter ca. $0.5 \mathrm{~cm}$ ) were added to the soil samples to break up soil aggregates. Samples were placed in an overhead shaker for $30 \mathrm{~min}$ at $30 \mathrm{rpm}$.

Suspensions of the arthropods, litter, and soil samples were spread onto Czapek Dox Iprodion Dichloran agar (CZID) [27], for litter and soil in a decimal dilution series using quarter-strength Ringer's solution with three replicate Petri dishes (diameter $9 \mathrm{~cm}$ ) each. For the arthropod samples, $0.2 \mathrm{~mL}$ and $0.3 \mathrm{~mL}$ of the undiluted suspension were spread on two Petri dishes, two replicates each. All Petri dishes were incubated at $25^{\circ} \mathrm{C}$ for 3 days without light followed by $2-4$ days under mixed black UV light (emission ca. $310-360 \mathrm{~nm}$ ) and with a photoperiod of 12:12 h of artificial daylight at room temperature. All germinated fungal propagules were counted as fungal colonies (colony forming units, $\mathrm{CFU}$ ). Fusarium fungi were identified on the genus level based on colony morphology. The total fungal abundance and the Fusarium spp. abundance were expressed per arthropod individual (TOTAL indiv ${ }^{-1}$, FUS indiv $^{-1}$ ) and per $1 \mathrm{~g}$ dried litter and soil (TOTAL g ${ }^{-1}$ DM, FUS $\left.\mathrm{g}^{-1} \mathrm{DM}\right)$.

Fusarium colonies were transferred onto potato dextrose agar (PDA, Carl Roth $\mathrm{GmbH}$ Karlsruhe, Germany) as well as Synthetic Nutrient-Poor Agar (SNA; [28]) for taxonomic identification to the species level and incubated as described before. Identification was carried out according to the guidelines of Leslie and Summerell [29] and Yli-Mattila et al. [30]. Fusarium fungi were isolated from all Petri dishes of the arthropod samples, from the $10^{-4}$ dilution of the litter samples and the $10^{-3}$ dilution of the soil samples. The number of germinated CFU on Petri dishes of these dilution levels was sufficiently high to detect rare Fusarium species and thus provide an overview of the Fusarium communities. At the 
same time, the number of CFU of Fusarium and other fungi was low enough to obtain uncontaminated single spore germination cultures of Fusarium fungi. The mean number of CFU per Petri dish was 196 for the $10^{-4}$ dilution of the litter samples and 79 for the $10^{-3}$ dilution of the soil samples. The resulting data were the basis for the comparison of the Fusarium species composition in the community analysis.

\subsection{Statistical Analysis}

The Fusarium species richness and dominance structure, as well as the total fungal and Fusarium abundance in soil and litter (number of colony forming units (CFU) per $1 \mathrm{~g}$ dry mass) and the load on the arthropods (CFU per individual), respectively, were analyzed in adapted statistical approaches. In a three factorial design, the factors "substrate type" (arthropod, litter, soil), "kettle hole" (7 kettle holes), and "sample point" (1-15) were defined. The factors "kettle hole" and "sampling point" were important due to the spatial dependency of arthropod, litter, and soil samples in the design. Note that 6 sampling points at kettle holes did not yield arthropod samples.

For all statistical analyses, the data of the arthropod samples were averaged across all individuals per sampling point. Abundance data of total fungi and Fusarium fungi were transformed $(\ln (x+1))$, and the abundance of the Fusarium species were standardized to dominances (0-100\%) for each sampling point. All statistical analysis were performed in $\mathrm{R}$ 4.1.1 [31]. Permutational analyses of variances (PerMANOVA) with the function "adonis2" in the package "vegan" were used to analyze differences in the taxonomic composition of Fusarium communities, followed by pair-wise analyses with the function "pairwise.adonis2" of the package "pairwiseAdonis" comparing pairs of factor levels [32]. All factors were included in the PerMANOVA as fixed factors. All resemblance matrices were based on Gower similarities between communities and were analyzed performing 9999 permutations with the permutation method "Permutation of residuals under a reduced model" [32]. To compare the three Fusarium communities visually, the effects of the factor "substrate type" on the taxonomic composition in terms of the dominance of species were visualized with nonmetric multidimensional scaling (nMDS) with the "ggvegan" package. To analyze the contribution of each fungal species to dissimilarities between the fungal communities of the different substrate types, a SIMPER analysis based on the Bray-Curtis dissimilarity index was performed with the function "simper" in the package "vegan".

To unravel potential relationships between the total fungal and Fusarium load on the body surface of arthropods and the total fungal and Fusarium abundance in soil and litter, a Spearman correlation matrix was calculated with the basic function "cor" and the function "corrplot" of the "corrplot" package. To test for a potential relationship between the taxonomic composition of the arthropod samples on the species composition of Fusarium, a Mantel test was conducted with the function "mantel" in the package "vegan".

\section{Results}

We collected 74 arthropods from six different orders on 15 out of 21 sampling points; Coleoptera was the most abundant taxa (Table S1). The body surface of 71 arthropod individuals had fungal propagules (colony forming units, CFU); the maximum was $8125 \mathrm{CFU}$ per individual. Propagules of Fusarium spp. were detected on 41 of the 74 arthropods, up to 64 CFU per individual. All litter and soil samples contained propagules of total fungi and of Fusarium spp. Total fungal abundance was on average more than 36 times lower in the soil than in the litter (Table 1). The untransformed descriptive data on the 74 arthropod samples are presented in Table S3. 
Table 1. Descriptive data of quantified total fungal (Tot) and Fusarium (Fus) colony forming units from the body surface of collected arthropods (Arthrop $\left(\operatorname{Indiv}^{-1}\right)$, and from litter and soil samples $\left(g^{-1} \mathrm{DM}\right)$.

\begin{tabular}{ccccccc}
\hline & \multicolumn{2}{c}{ Arthrop (Indiv $\left.^{-1}\right)$} & \multicolumn{2}{c}{ Litter $\left.\mathbf{( g}^{-\mathbf{1}} \mathbf{D M}\right)$} & \multicolumn{2}{c}{ Soil $\left(\mathbf{g}^{-\mathbf{1}} \mathbf{D M}\right)$} \\
\hline & Tot & Fus & Tot & Fus & Tot & Fus \\
\hline Min. & 23.80 & 0.00 & 64.01 & 0.39 & 4.33 & 0.05 \\
1st Qu. & 85.27 & 2.12 & 124.51 & 2.38 & 5.99 & 0.21 \\
Median & 107.85 & 3.44 & 257.87 & 3.83 & 7.48 & 0.35 \\
Mean & 452.47 & 9.96 & 300.09 & 7.12 & 8.23 & 0.36 \\
3rd Qu. & 215.67 & 10.78 & 406.18 & 7.80 & 9.46 & 0.45 \\
Max. & 4447.00 & 64.00 & 755.80 & 47.67 & 14.92 & 0.93 \\
\hline
\end{tabular}

3.1. Total Fungal and Fusarium Load on the Body Surface of Arthropods and Fungal Abundances in SOIL and Litter

The Fusarium load on the body surface of arthropods correlated significantly and negatively with the total fungal abundance in the soil $\left(\mathrm{r}_{\mathrm{sp}}=-0.61, p=0.03\right.$, Figure 2a) and significantly and positively with the total fungal load on the arthropods $\left(\mathrm{r}_{\mathrm{sp}}=0.78\right.$, $p<0.001$; Figure 2b). Arthropods with a high total fungal load also showed a high Fusarium load. No other significant correlations were detected between total fungal and Fusarium abundance or between fungal loads of different substrates (Figure 3).

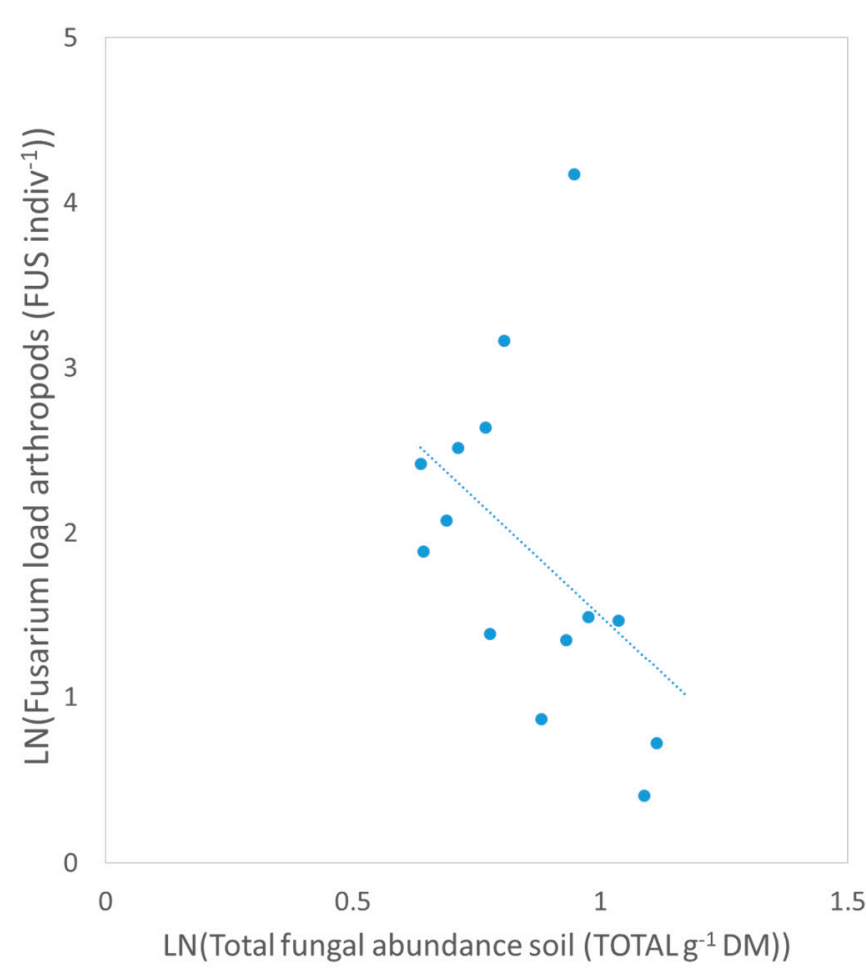

(a)

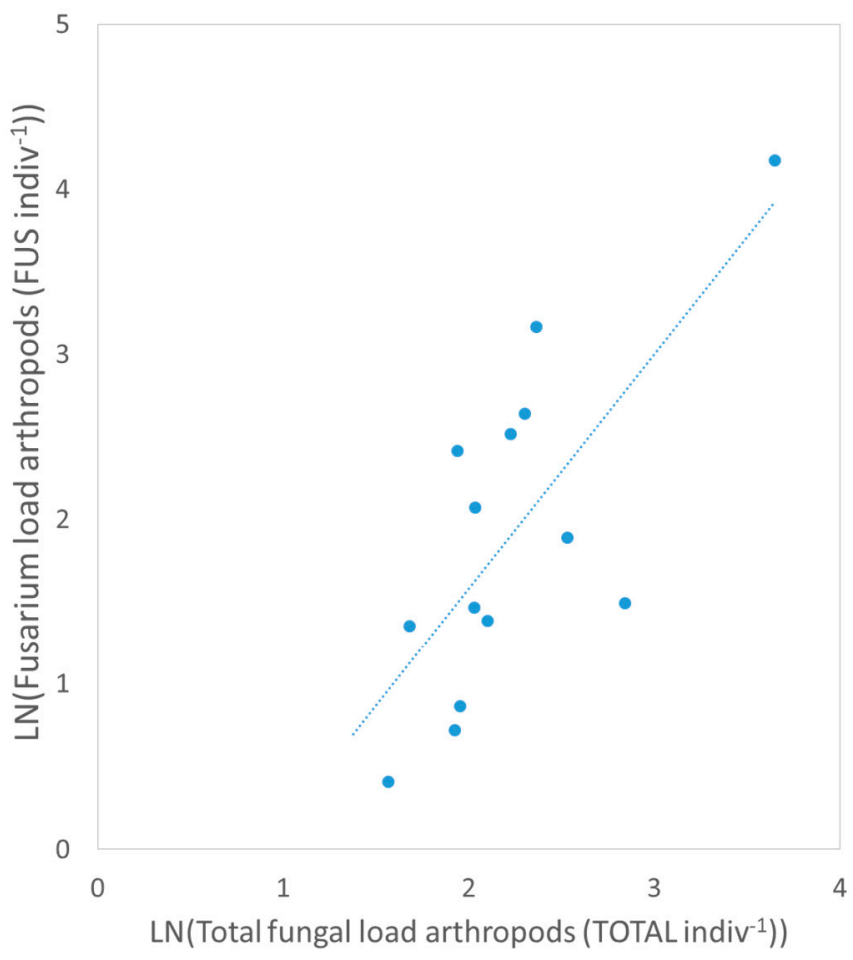

(b)

Figure 2. Relationship of the Fusarium load (FUS indiv ${ }^{-1}$ ) on the body surface of ground-dwelling arthropods to (a) the total fungal abundance (TOTAL g ${ }^{-1}$ DM) in the soil, (b) the total fungal load (TOTAL indiv $^{-1}$ ) on the body surface of ground-dwelling arthropods detected as number of colony forming units (CFU) with culture-dependent method. All data are transformed $\mathrm{LN}(\mathrm{x}+1)$. 


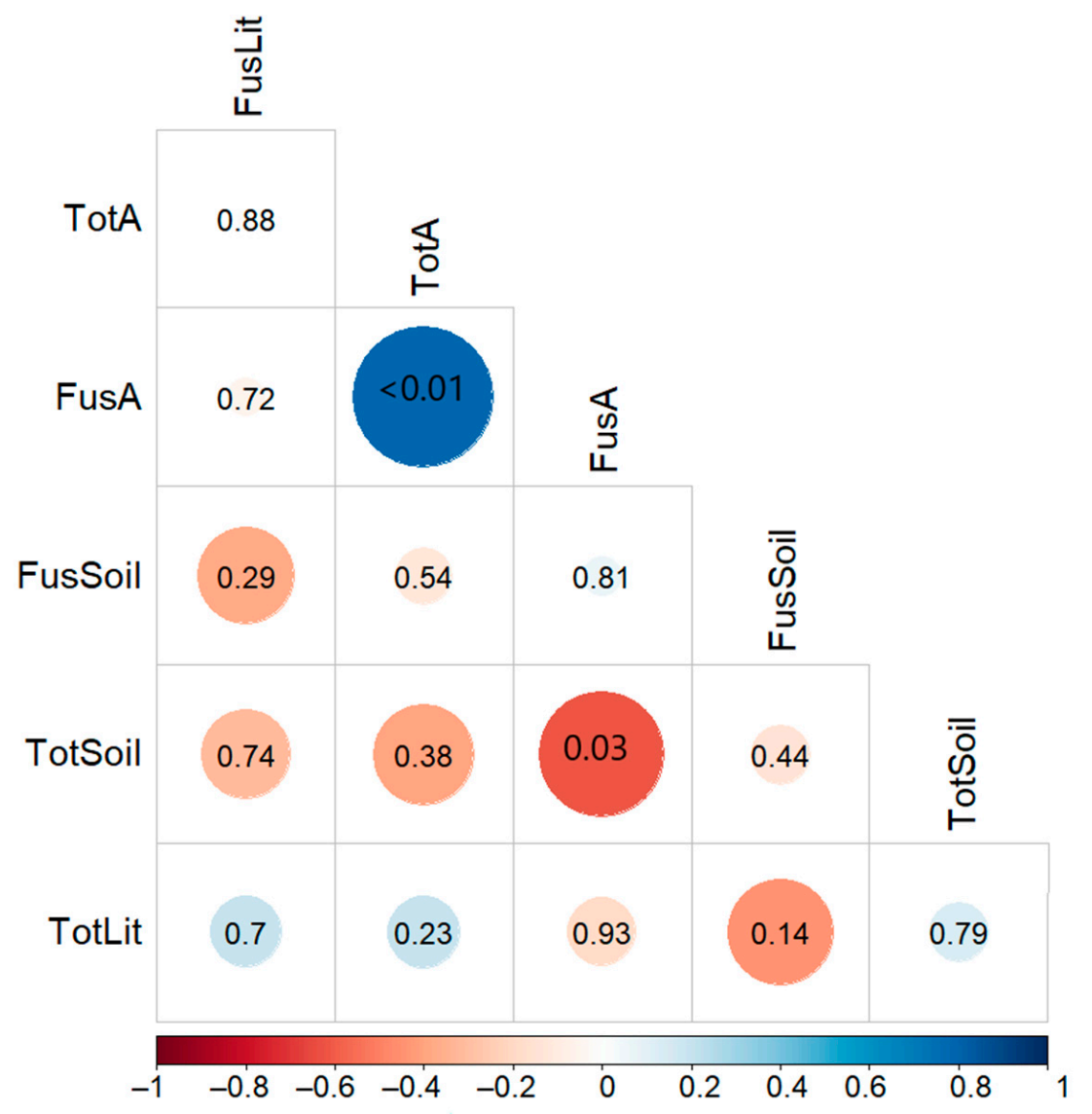

Figure 3. Correlation matrix with the Spearman correlation coefficients between the total fungal (Tot) and Fusarium (Fus) load on the body surface of arthropods (A), and abundance of Fusarium and total fungi in soil (Soil) and litter (Lit) samples, respectively. Darker colors and larger circles indicate stronger correlations. $p$-values are given for each correlation.

\subsection{Fusarium Species Richness and Composition in Different Substrate Types}

In total, 17 Fusarium species were detected from the body surface of arthropods and from litter and soil samples (Table S4). The substrate type significantly affected the Fusarium species richness (Table 2). The body surface of arthropods on average had significantly more Fusarium species per sample than observed in litter and soil samples. The species richness of litter and soil samples did not differ significantly (Figure 4). The Fusarium community on the body surface of arthropods consisted of 15 species in total. In the litter of the kettle hole vegetation, 12 species were observed and in the soil of wheat fields, 13 species were observed in total.

Fusarium culmorum was the most common species in all three substrates and accounted for $42 \%$ of all detected Fusarium spp. on the arthropods (Figure 5). Table S4 shows the total sums of each identified Fusarium species detected on all 74 collected arthropods as well as in the litter samples at $10^{-4}$ and soil samples at $10^{-3}$ dilution levels. The mean abundances of each Fusarium species per sampling point are shown for the arthropods, litter, and soil samples in Tables S5-S7. F. equiseti was only found on the body surface of arthropods with a low percentage of $2.5 \%$ of all identified species. However, F. equiset $i$ was present in five out 15 arthropod samples. F. proliferatum and F. tricinctum were not identified from the body surface of arthropods and were rarely observed in the litter and soil samples (Figure 5). F. dimerum was frequently isolated from litter samples, and accounted for $16.0 \%$ of all detected Fusarium spp. in the litter, but were rarely found in soil samples. However, F. solani and F. crookwellense showed the opposite pattern being often isolated from soil and accounted for $13.2 \%$ and $9.4 \%$, respectively, of all detected Fusarium spp. in the soil (Figure 5). 
Table 2. Effects of the different kettle holes, sampling points and substrate types arthropods (A), litter (L), soil (S) on the species composition of Fusarium communities based on relative abundances (Dominance) and the number of identified Fusarium species (Richness) in (A) the global model and (B) pairwise post-hoc tests. Significant $p$-values from PerMANOVA are shown in bold.

\begin{tabular}{cccccc}
\hline & \multicolumn{3}{c}{ Dominance } & \multicolumn{2}{c}{ Richness } \\
\hline (A) Global Model & df & F & $p$ & F & $p$ \\
\hline Kettle hole & 6 & 1.24 & 0.143 & 1.1 & 0.371 \\
Sampling point & 14 & 1.08 & 0.305 & 1.19 & 0.328 \\
Substrate type & 2 & 4.9 & $<0.001$ & 12.29 & $<\mathbf{0 . 0 0 1}$ \\
\hline (B) Pairwise Comparison & & & & & \\
\hline A $\times$ L & 1 & 3.24 & $\mathbf{0 . 0 0 2}$ & 24.41 & $\mathbf{0 . 0 0 1}$ \\
A $\times$ S & 1 & 4.46 & $\mathbf{0 . 0 0 1}$ & 16.84 & $\mathbf{0 . 0 0 2}$ \\
S $\times$ L & 1 & 6.05 & $\mathbf{0 . 0 0 1}$ & 0.67 & 0.492 \\
\hline
\end{tabular}

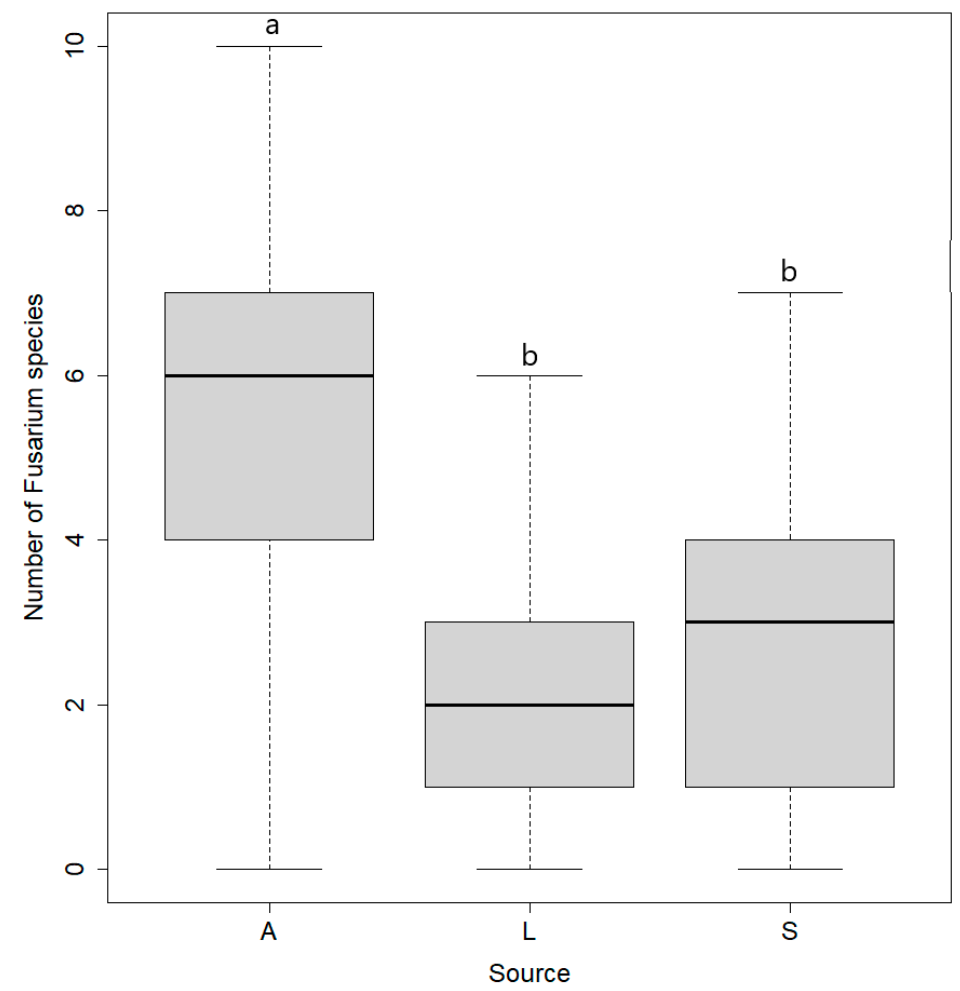

Figure 4. Number of identified Fusarium species on the body surface of arthropods (A), in samples of litter (L) and soil (S). The midline of all boxplots represents the median, with the upper and lower limits of the box being the third and first quartile, respectively. Whiskers will extend up to 1.5 times the interquartile range from the top/bottom of the box. Different letters above the boxplots indicate significant differences. 


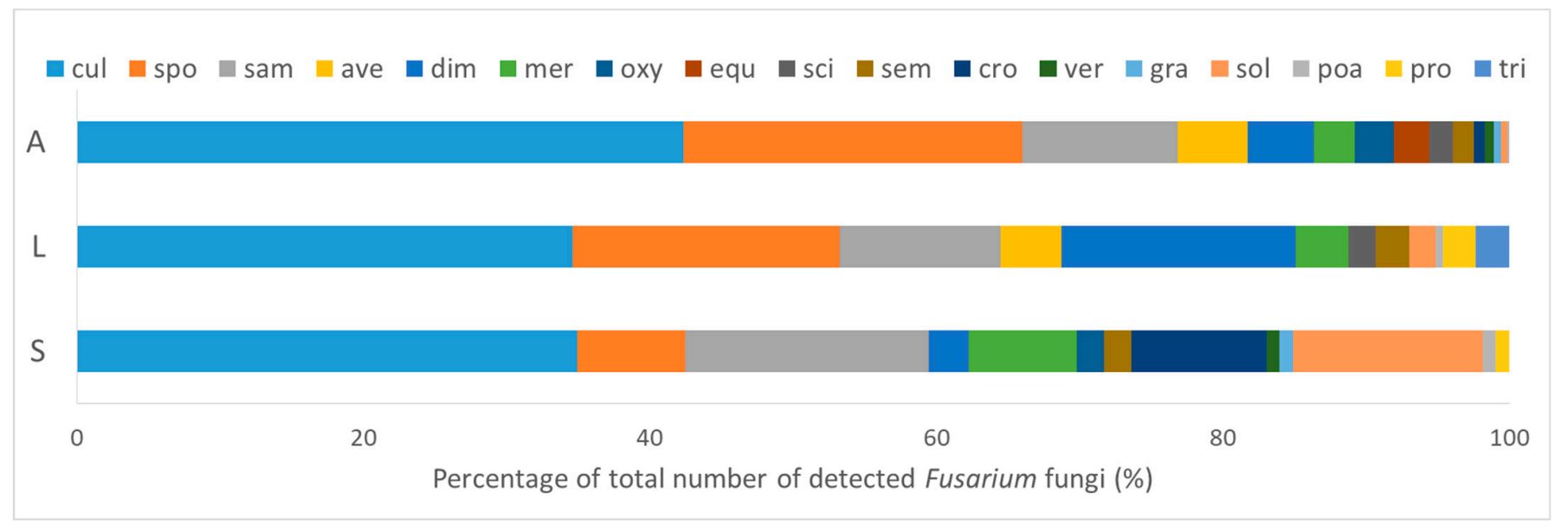

Figure 5. Dominance structure as percentage of each Fusarium (F.) species of the total number of detected Fusarium colony forming units (CFU), isolated from the body surface of ground-dwelling arthropods (A, CFU indiv ${ }^{-1}$ ), litter (L), and soil (S) (CFU g $\left.{ }^{-1} \mathrm{DM}\right)$. Species code: F. culmorum (cul), F. sporotrichioides (spo), F. sambucinum (sam), F. avenaceum (ave), F. dimerum (dim), F. merismoides (mer), F. oxysporum (oxy), F. equiseti (equ), F. scirpi (sci), F. semitectum (sem), F. crookwellense (cro), F. verticillioides (ver), F. graminearum (gra), F. solani (sol), F. poae (poa), F. proliferatum (pro), F. tricinctum (tri).

In general, the Fusarium species composition of different substrate types differed significantly in terms of relative abundances (Table 2). All three substrates showed a distinct composition of Fusarium species based on their relative abundances, but the ordination also indicates moderate overlap between arthropod and litter communities (Figure 6). The most influential species for discriminating the Fusarium communities between pairs of substrate types were F. sporotrichioides, F. culmorum, and F. sambucinum (Table 3). The composition of the analyzed arthropod taxa at each sampling point was not significantly related to the species composition of Fusarium communities on the body of arthropods at each sample point (Mantel: $\mathrm{R}=-0.04, p=0.55$ ).

Table 3. Cumulative percentage contribution (Cum. Con. Up to a threshold of 50\%) to the difference between communities by the Fusarium species that differentiate most between pairs of substrate types according to similarity percentage analysis.

\begin{tabular}{|c|c|c|c|c|c|}
\hline \multicolumn{2}{|c|}{ Arthropods vs. Litter } & \multicolumn{2}{|c|}{ Arthropods vs. Soil } & \multicolumn{2}{|c|}{ Litter vs. Soil } \\
\hline Species & Cum. Con & Species & Cum. Con & Species & Cum. Con \\
\hline F. sporotrichioides & 0.23 & F. culmorum & 0.24 & F. culmorum & 0.22 \\
\hline F. culmorum & 0.42 & F. sambucinum & 0.39 & F. sporotrichioides & 0.43 \\
\hline F. dimerum & 0.57 & F. dimerum & 0.52 & F. sambucinum & 0.56 \\
\hline
\end{tabular}




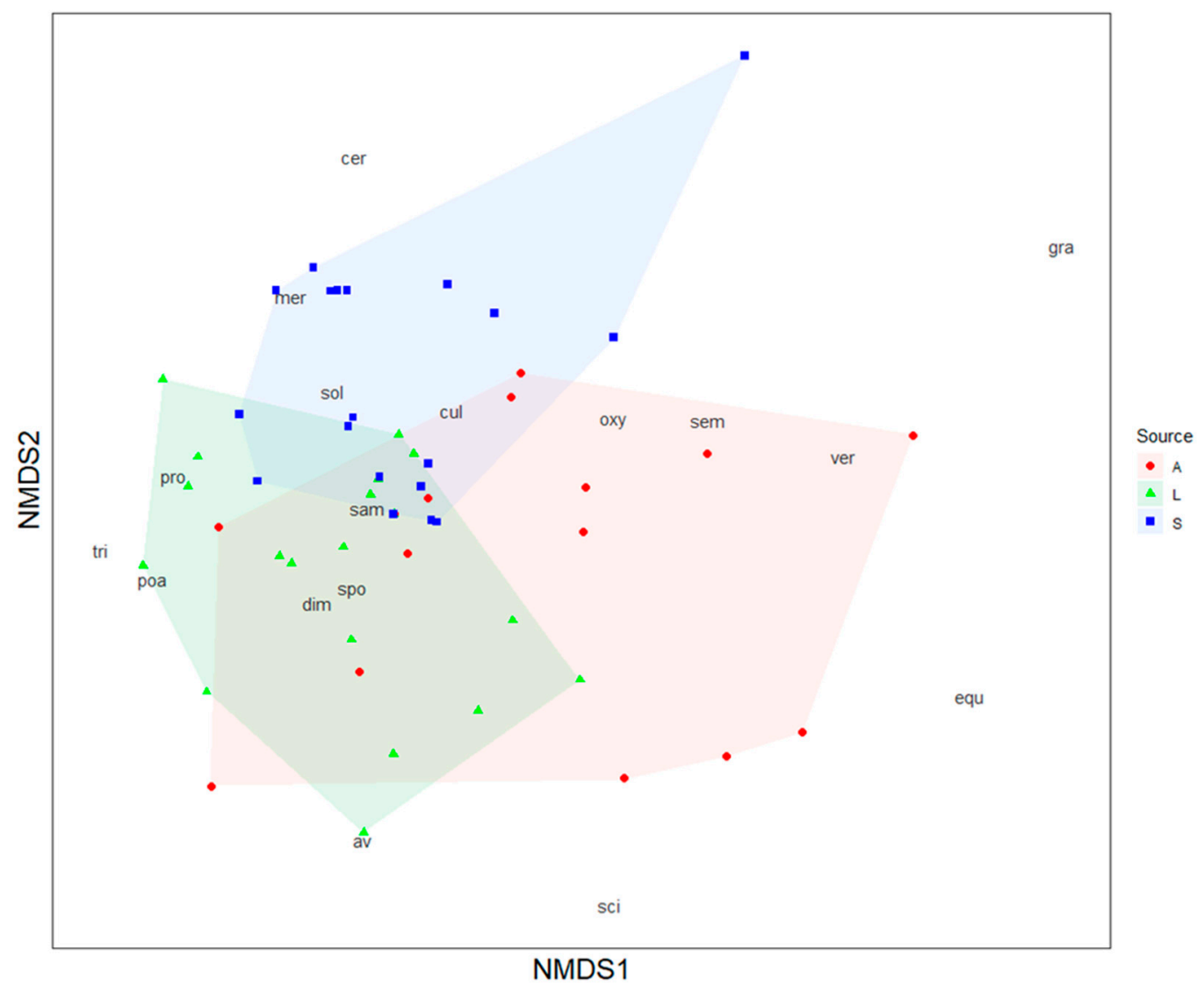

Figure 6. Non-metric multi-dimensional scaling (NMDS) ordination based on the Gower distance matrix of the Fusarium (F.) species dominance structure, isolated from the body surface of grounddwelling arthropods (A), from litter samples of kettle hole margins (L), or soil from the adjacent winter wheat field (S). Resemblance in the dominance structure between the three substrate is shown in symbols. The symbols represent samples; samples that are very distinct from each other are further away in the plot. The abbreviations indicate Fusarium species. Species code: F. avenaceum (ave), F. crookwellense (cer), F. culmorum (cul), F. dimerum (dim), F. equiseti (equ), F. graminearum (gra), F. merismoides (mer), F. oxysporum (oxy), F. poae (poa), F. proliferatum (pro), F. sambucinum (sam), F. scirpi (sci), F. semitectum (sem), F. solani (sol), F. sporotrichioides (spo), F. tricinctum (tri), F. verticillioides (ver).

\section{Discussion}

Viable propagules of different fungal genera were detected on the body surface of most of the investigated arthropods (96\%). Viable Fusarium propagules were also detected on the majority of arthropods (55\%). These results suggest that ground-dwelling arthropods frequently interact with fungi of different taxa and that fungal propagules stay viable on the body surface of the arthropods. In an experimental study, propagules of F. acuminatum Ellis \& Everhart stayed viable on an insect vector for $96 \mathrm{~h}$ after exposure [33]. Arthropods have a high potential to act as vectors for propagules of Fusarium spp. and other fungal genera. Considerably lower frequencies of phytopathogenic fungi were detected on arthropods potentially vectoring for the Fusarium wilt of banana, caused by F. oxysporum, and the vine trunk disease $[17,34]$.

The positive correlation between the Fusarium load and the total fungal load on the arthropods was strong $\left(\mathrm{r}_{\mathrm{sp}}=0.78\right)$, which coincides with a previous study on grounddwelling carabid beetles [18]. Fungi of the genera Fusarium, Penicillium, Epicoccum, Cladosporium, Aspergillus, and yeasts such as Candida are commonly found on the surface of arthropods [35-37]. The strong correlation between total fungi and Fusarium fungi suggests that no selective mechanism exists that either reduces or promotes the attachment of Fusarium propagules to the body surface of arthropods in comparison to other fungal propagules. 
In general, volatile organic compounds (VOCs) can be recognized by arthropods and play an important role in their orientation and predation behavior [38,39]. The VOCs emitted by plants infected by Fusarium fungi can be attractive to some arthropods that vector these pathogens and change their behavior accordingly [40,41]. However, these microbially produced volatiles can also be repellant for other arthropods, and the mycotoxins produced by the Fusarium fungi can reduce the fitness of arthropods [39,42].

The Fusarium load on the arthropods only correlated significantly with the total fungal abundance in the soil of the crop field $\left(\mathrm{r}_{\mathrm{sp}}=-0.61\right)$, supporting our first hypothesis, which expected an effect of the litter and soil fungal abundance on the fungal load of the arthropods partly. No relationships were detected between the total fungal load of the arthropods and the soil, or between the litter and soil. This suggests that other factors affect the total fungal and Fusarium distribution, which were not investigated in this study, such as soil humidity, air temperature, or management practices. Previous studies show that a humid and cold micro-climate increases the abundance of Fusarium spp. but decreases the abundance of Alternaria spp., another common phytopathogenic fungi, and that the application of residual manure and crop rotation affects the microbial composition in maize fields $[43,44]$. Further studies should aim for a metabarcoding analysis of the mycobiome in the soil, litter, and on the arthropods to identify the entire fungal community at a species level. Including abiotic and biotic environmental factors of the soil and adjacent seminatural habitats such as soil moisture in further studies would help to detect relationships between the fungal loads of potential vectors and the fungal abundance in their habitats. Further studies should include the soil in the semi-natural habitats, as well as wheat plants and the crop residuals in the arable fields since they are an important inoculum source for Fusarium spp. [8]. A contamination of the external fungal load of the arthropods with fungal propagules from the feces or other body secretes cannot be excluded and should be addressed in further studies.

The body surface of arthropods had more Fusarium species (in total and on average) than in litter and soil samples, which confirms our second hypothesis. The species composition of Fusarium communities on arthropods consisted of species found in litter samples of the kettle hole margins as well as in the soil of the arable field. These results indicate that arthropods may exchange fungal propagules between the semi-natural habitats and the arable fields. F. equiseti was unique for arthropods and was detected frequently in low concentrations. This indicates that arthropods contact with fungal propagules of $F$. equiseti at crop residuals in the crop field or in areas closer to the kettle hole, which were not sampled in this study. In other studies, F. equiseti was regularly detected on ground beetles, soil, and senescent or damaged plant tissue [18,29]. F. proliferatum and F. tricinctum were present in the litter or soil samples in low frequencies and concentrations. Therefore, it is very likely that they were simply not detected on the body surface of arthropods due to their local rarity. In general, the most abundant Fusarium species F. culmorum, F. dimerum, F. sambucinum, F. sporotrichioides, and F. solani were also commonly found on the body surface of the investigated arthropods. The results imply that the transport of Fusarium propagules by ground-dwelling arthropods is not selective and is not limited to certain Fusarium species in terms of adhesion as well as survival on the body surface of the arthropods. If species are missing on the body surface of arthropods, they are rare in soil and litter, and if species are only present on the body surface, they were probably introduced from other habitats.

Fusarium head blight (FHB) is one of the most important diseases in wheat production and is caused by a complex of 19 Fusarium species [5,6]. Within this complex, species differ in their ecology, virulence, and mycotoxin production and therefore in their importance for the development of FHB and its economic consequences [6]. F. culmorum is one of the main agents of FHB and accounted for a major proportion of the Fusarium spp. identified here. Therefore, these results might be relevant to the management of this plant disease. F. culmorum has already been identified on ground beetles, wheat stem sawflys (Cephus cinctus Norton), and is commonly found in soil and on plant debris [18,29,45]. All Fusarium 
species detected in this study were morphologically determined and were based on viable exogenous propagules. Therefore, a genetic approach that examines the entire fungal load of arthropods (endogenous and exogenous) and distinguishes Fusarium species by genetic traits should be addressed in further studies.

Fusarium fungi produce different types of propagules, which can be detected with culture-dependent methods. Some Fusarium species can produce smaller, often unicellular microconidia in addition to sickle-shaped, multicellular macroconidia [29]. Chlamydospores, which are thick-walled large resting spores, and the sexually produced ascospores are also typical for some Fusarium species [29]. Propagules of Fusarium fungi are commonly distributed by wind, rain splash, or by arthropods [33,46,47]. However, a previous study investigating the dispersal of spores of different Fusarium species by wind suggests a combination of the different dispersal mechanisms [48]. The different spore types of the Fusarium fungi did not affect the probability to adhere to the body surface of the arthropods in this study. Analyses at the species level of the entire fungal community in the soil, litter, and on the body surface of the arthropods could provide information on whether this is also the case for other fungal genera.

The results contradict the third hypothesis; the Fusarium species composition in terms of relative abundances on the body surface of the arthropods differed from that in soil and litter. F. culmorum occupied a considerably larger proportion in the Fusarium community on the arthropods than in soil and litter. Most Fusarium species were present in all three substrates, as described before. However, they differed in their relative abundance, so that the arthropods, litter, and soil samples displayed distinct Fusarium communities. Seminatural habitats as well as crop fields are crucial habitats for ground-dwelling arthropods, and they can move between both habitat types, e.g., via spillover effects [14,20]. Arthropods interact with fungi in both the soil of the fields and the litter of the kettle holes, both of which had distinct fungal communities in this study. Therefore, the distinct Fusarium community on the arthropods probably results from an interaction with Fusarium communities in both habitats. The NMDS revealed more similarities between the arthropod and the litter Fusarium community than with the soil. This could be explained by the high importance of semi-natural habitats for many animal species such as ground beetles, spiders, and bees [22,49]. The experimental design, placing the traps $1 \mathrm{~m}$ away from the margin of the kettle hole, probably also influenced the results. However, it also showed a clearer picture of the fungal load of the arthropods leaving the kettle hole and possibly spreading fungal propagules into the crop fields. Nevertheless, the arthropods' Fusarium community also showed similarities with the soil of the crop field, but the overlap was much smaller. Sampling arthropods within crop fields at different distances from semi-natural habitats could improve the understanding of the relationship between the fungal community on the arthropods and the environmental fungal communities.

\section{Conclusions}

Ground-dwelling arthropods revealed a remarkable potential to spread phytopathogenic and other fungi into arable fields. They interacted with the Fusarium community in the litter of semi-natural habitats as well as in the soil of adjacent crop fields, displaying a distinct and very species-rich Fusarium community. Exogenous dispersal by arthropods did not favor or hinder spores of specific Fusarium species. These results might be important for understanding fungal community dynamics and spatiotemporal disease patterns in crop fields. In addition to other dispersal mechanisms such as wind, arthropods could lead to a link between micro-communities and habitats. Further studies should analyze a broader range of fungal species by using a metabarcoding approach and by sampling arthropods within crop fields at different distances from semi-natural habitats. This could provide more insights about how the fungal community on the arthropods relates to environmental fungal communities. 
Supplementary Materials: The following are available online at https:/ /www.mdpi.com/article/10 .3390 / microorganisms10020335/s1, Table S1: Number of collected individuals (N indiv) of different arthropod orders, Table S2: Vegetation survey of seven kettle hole margins of 21 plots [50], Table S3: Untransformed descriptive data of the quantified total fungal and Fusarium load (CFU Indiv ${ }^{-1}$ ) of 74 collected arthropods, Table S4: Number of colony forming units (CFU) of Fusarium species detected on the body surface of 74 collected arthropods, Table S5: Dominance structure as number of colony forming units of Fusarium species detected on the body surface of collected arthropods, Table S6: Dominance structure as number of colony forming units of each Fusarium species detected in $1.0 \mathrm{mg}$ dry mass of litter samples, Table S7: Dominance structure as number of colony forming units of Fusarium species detected in $1.0 \mathrm{mg}$ dry mass of soil samples.

Author Contributions: Conceptualization, M.E.H.M., M.G. and N.H.; methodology, M.E.H.M. and N.H.; software, K.B. and N.H.; validation, K.B. and N.H.; formal analysis, K.B. and N.H.; investigation, N.H.; resources, M.E.H.M. and M.G.; data curation, N.H.; writing-original draft preparation, N.H.; writing-review and editing, N.H., M.E.H.M., M.G. and K.B.; visualization, N.H.; supervision, M.E.H.M., K.B. and M.G.; project administration, M.E.H.M. and M.G.; funding acquisition, M.E.H.M. and M.G. All authors have read and agreed to the published version of the manuscript.

Funding: This study was core financed by the Brandenburgian Ministry of Science, Research and Culture (MWFK) and the German Federal Ministry of Food and Agriculture (BMEL). The project is associated with the BioMove Research Training Group (DFG-GRK 2118/1-2).

Institutional Review Board Statement: Not applicable.

Informed Consent Statement: Not applicable.

Data Availability Statement: The data presented in this study are available on request from the corresponding author.

Acknowledgments: Special thanks to Cornelia Fischer, Martina Peters, Petra Lange, Klarissa Kober, and Marina Gerling for their help in the field and in the laboratory. Special thanks to Ralph Platen and Simon Lewin for their help in the data analysis.

Conflicts of Interest: The authors declare no conflict of interest. The funders had no role in the design of the study; in the collection, analyses, or interpretation of data; in the writing of the manuscript; or in the decision to publish the results.

\section{References}

1. Lundberg, J.; Moberg, F. Mobile link organisms and ecosystem functioning: Implications for ecosystem resilience and management. Ecosystems 2003, 6, 87-98. [CrossRef]

2. Kurtz, B.; Karlovsky, P.; Vidal, S. Interaction Between Western Corn Rootworm (Coleoptera: Chrysomelidae) Larvae and Root-Infecting Fusarium verticillioides. Environ. Entomol. 2010, 39, 1532-1538. [CrossRef] [PubMed]

3. Sobek, E.A.; Munkvold, G.P. European corn borer (Lepidoptera: Pyralidae) larvae as vectors of Fusarium moniliforme, causing kernel rot and symptomless infection of maize kernels. J. Econ. Entomol. 1999, 92, 503-509. [CrossRef]

4. Mayfield, A.E.; Peña, J.E.; Crane, J.H.; Smith, J.A.; Branch, C.L.; Ottoson, E.D.; Hughes, M. Ability of the redbay ambrosia beetle (Coleoptera: Curculionidae: Scolytinae) to bore into young avocado (Lauraceae) plants and transmit the laurel wilt pathogen (Raffaelea sp.). Fla. Entomol. 2008, 91, 485-487. [CrossRef]

5. Parry, D.W.; Jenkinson, P.; McLeod, L. Fusarium ear blight (scab) in small grain cereals-a Review. Plant Pathol. 1995, 44, 207-238. [CrossRef]

6. Champeil, A.; Doré, T.; Fourbet, J. Fusarium head blight: Epidemiological origin of the effects of cultural practices on head blight attacks and the production of mycotoxins by Fusarium in wheat grains. Plant Sci. 2004, 166, 1389-1415. [CrossRef]

7. Pereyra, S.A.; Dill-Macky, R. Colonization of the residues of diverse plant species by Gibberella zeae and their contribution to fusarium head blight inoculum. Plant Dis. 2008, 92, 800-807. [CrossRef]

8. Landschoot, S.; Audenaert, K.; Waegeman, W.; Pycke, B.; Bekaert, B.; De Baets, B.; Haesaert, G. Connection between primary Fusarium inoculum on gramineous weeds, crop residues and soil samples and the final population on wheat ears in Flanders, Belgium. Crop Prot. 2011, 30, 1297-1305. [CrossRef]

9. Postic, J.; Cosic, J.; Vrandecic, K.; Jurkovic, D.; Saleh, A.A.; Leslie, J.F. Diversity of Fusarium Species Isolated from Weeds and Plant Debris in Croatia. J. Phytopathol. 2012, 81, 76-81. [CrossRef]

10. Suproniene, S.; Kadziene, G.; Irzykowski, W.; Sneideris, D.; Ivanauskas, A.; Sakalauskas, S.; Serbiak, P.; Svegzda, P.; Auskalniene, O.; Jedryczka, M. Weed species within cereal crop rotations can serve as alternative hosts for Fusarium graminearum causing Fusarium head blight of wheat. Fungal Ecol. 2019, 37, 30-37. [CrossRef] 
11. Dromph, K.M. Dispersal of entomopathogenic fungi by collembolans. Soil Biol. Biochem. 2001, 33, 2047-2051. [CrossRef]

12. Guillen Sánchez, C.; Tixier, P.; Tapia Fernández, A.; Conejo Barboza, A.M.; Sandoval Fernández, J.A.; de Lapeyre de Bellaire, L. Can the banana weevil Cosmopolites sordidus be a vector of Fusarium oxysporum f.sp. cubense race 1? Unravelling the internal and external acquisition of effective inoculum. Pest Manag. Sci. 2021, 77, 3002-3012. [CrossRef] [PubMed]

13. Mannino, M.C.; Huarte-Bonnet, C.; Davyt-Colo, B.; Pedrini, N. Is the Insect Cuticle the only Entry Gate for Fungal Infection? Insights into Alternative Modes of Action of Entomopathogenic Fungi. J. Fungi 2019, 5, 33. [CrossRef] [PubMed]

14. Holland, J.M. Carabid beetles: Their ecology, survival, and use in agroecosystems. In The Agroecology of Carabid Beetles; Holland, J.M., Ed.; Intercept Limited: Andover, UK, 2002; Volume 62, pp. 1-40.

15. Harding, P.T.; Sutton, S.L. Woodlice in Britain and Ireland:Distribution and Habitat; Natural Environment Research Counsil-Institute of Terrestrial Ecolog: Huntingdon, UK, 1985; ISBN 0-904282-85-6.

16. Anslan, S.; Bahram, M.; Tedersoo, L. Temporal changes in fungal communities associated with guts and appendages of Collembola as based on culturing and high-throughput sequencing. Soil Biol. Biochem. 2016, 96, 152-159. [CrossRef]

17. Moyo, P.; Allsopp, E.; Roets, F.; Mostert, L.; Halleen, F. Arthropods Vector Grapevine Trunk Disease Pathogens. Phytopathology 2014, 104, 1063-1069. [CrossRef]

18. Heitmann, N.; Glemnitz, M.; Lentzsch, P.; Platen, R.; Müller, M.E.H. Quantifying the Role of Ground Beetles for the Dispersal of Fusarium and Alternaria Fungi in Agricultural Landscapes. J. Fungi 2021, 7, 863. [CrossRef]

19. Dillard, H.R.; Cobb, A.C.; Lamboy, J.S. Transmission of Alternaria brassicicola to Cabbage by Flea Beetles (Phyllotreta cruciferae). Plant Dis. 1998, 82, 153-157. [CrossRef]

20. Birkhofer, K.; Fevrier, V.; Heinrich, A.E.; Rink, K.; Smith, H.G. The contribution of CAP greening measures to conservation biological control at two spatial scales. Agric. Ecosyst. Environ. 2018, 255, 84-94. [CrossRef]

21. Lozada-Gobilard, S.; Stang, S.; Pirhofer-Walzl, K.; Kalettka, T.; Heinken, T.; Schröder, B.; Eccard, J.; Joshi, J. Environmental filtering predicts plant-community trait distribution and diversity: Kettle holes as models of meta-community systems. Ecol. Evol. 2019, 9, 1898-1910. [CrossRef]

22. Platen, R.; Kalettka, T.; Ulrichs, C. Kettle Holes in the Agrarian Landscape: Isolated and Ecological Unique Habitats for Carabid Beetles (Col.: Carabidae) and Spiders (Arach.: Araneae). J. Landsc. Ecol. 2016, 9, 29-60. [CrossRef]

23. The Leibniz Centre for Agricultural Landscape Research (ZALF) AgroScapeLab Quillow (ASLQ). Available online: https: / / www.zalf.de/de/struktur/eip/Seiten/AgroScapeLab.aspx (accessed on 1 July 2021).

24. Kalettka, T.; Rudat, C. Hydrogeomorphic types of glacially created kettle holes in North-East Germany. Limnologica 2006, 36, 54-64. [CrossRef]

25. Stresemann, E. Exkursionsfauna von Deutschland-Band 2 Wirbellose: Insekten, 11th ed.; Spektrum Verlag: Heidelberg, Germany, 2011; pp. $45-572$.

26. Müller, T.; Ruppel, S.; Behrendt, U.; Lentzsch, P.; Müller, M.E.H. Antagonistic Potential of Fluorescent Pseudomonads Colonizing Wheat Heads Against Mycotoxin Producing Alternaria and Fusaria. Front. Microbiol. 2018, 9, 2124. [CrossRef] [PubMed]

27. Abildgren, M.P.; Lund, F.; Thrane, U.; Elmholt, S. Czapek-Dox agar containing iprodione and dicloran as a selective medium for the isolation of Fusarium species. Lett. Appl. Microbiol. 1987, 5, 83-86. [CrossRef]

28. Nierenberg, H. Untersuchungen über die morphologische und biologische Differenzierung in der Fusarium-Sektion Liseola. In Mitteilungen aus der Biologischen Bundesanstalt für Land-und Forstwirtschaft Berlin-Dahlem-169; Kommissionsverlag Paul Parey: Berlin, Germany; Hamburg, Germany, 1976; ISBN 3-489-16900-X.

29. Leslie, J.F.; Summerell, B.A. The Fusarium Laboratory Manual, 1st ed.; Blackwell Publishing: Ames, IA, USA, 2006; ISBN 9780813819198.

30. Yli-Mattila, T.; Hussien, T.; Gavrilova, O.; Gagkaeva, T. Morphological and molecular variation between Fusarium avenaceum, Fusarium arthrosporioides and Fusarium anguioides strains. Pathogens 2018, 7, 94. [CrossRef]

31. R Core Team R: A Language and Environment for Statistical Computing. Available online: https://www.r-project.org/ (accessed on 1 July 2021).

32. Anderson, M.J. A new method for non-parametric multivariate analysis of variance. Austral Ecol. 2001, 26, 32-46. [CrossRef]

33. El-Hamalawi, Z.A. Acquisition, retention and dispersal of soilborne plant pathogenic fungi by fungus gnats and moth flies. Ann. Appl. Biol. 2008, 153, 195-203. [CrossRef]

34. Meldrum, R.A.; Daly, A.M.; Tran-Nguyen, L.T.T.; Aitken, E.A.B. Are banana weevil borers a vector in spreading Fusarium oxysporum f. sp. cubense tropical race 4 in banana plantations? Australas. Plant Pathol. 2013, 42, 543-549. [CrossRef]

35. Yun, T.; Park, S.; Yu, J.; Hwang, Y.; Hong, K. Isolation and Identification of Fungal Species from the Insect Pest Tribolium castaneum in Rice Processing Complexes in Korea. Plant Pathol. J. 2018, 34, 356-366. [CrossRef]

36. Bezos, D.; Martínez-álvarez, P.; Sanz-Ros, A.V.; Martín-García, J.; Fernandez, M.M.; Diez, J.J. Fungal communities associated with bark beetles in Pinus radiata plantations in Northern Spain affected by pine pitch canker, with special focus on Fusarium species. Forests 2018, 9, 698. [CrossRef]

37. Blodgett, J.T.; Swart, W.J.; Louw, S.V.M. Identification of fungi and fungal pathogens associated with Hypolixus haerens and decayed and cankered stems of Amaranthus hybridus. Plant Dis. 2004, 88, 333-337. [CrossRef]

38. Oster, M.; Smith, L.; Beck, J.J.; Howard, A.; Field, C.B. Orientation behavior of predaceous ground beetle species in response to volatile emissions identified from yellow starthistle damaged by an invasive slug. Arthropod. Plant Interact. 2014, 8, $429-437$. [CrossRef] 
39. Ponce, M.A.; Kim, T.N.; Morrison, W.R. A systematic review of the behavioral responses by stored-product arthropods to individual or blends of microbially produced volatile cues. Insects 2021, 12, 391. [CrossRef] [PubMed]

40. Nordlander, G.; Eidmann, H.H.; Jacobsson, U.; Nordenhem, H.; Sjödin, K. Orientation of the pine weevil Hylobius abietis to underground sources of host volatiles. Entomol. Exp. Appl. 1986, 41, 91-100. [CrossRef]

41. Bartelt, R.J.; Wicklow, D.T. Volatiles from Fusarium verticillioides (Sacc.) Nirenb. and Their Attractiveness to Nitidulid Beetles. J. Agric. Food Chem. 1999, 47, 2447-2454. [CrossRef] [PubMed]

42. Drakulic, J.; Caulfield, J.; Woodcock, C.; Jones, S.P.T.; Linforth, R.; Bruce, T.J.A.; Ray, V. Sharing a Host Plant (Wheat [Triticum aestivum]) Increases the Fitness of Fusarium graminearum and the Severity of Fusarium Head Blight but Reduces the Fitness of Grain Aphids (Sitobion avenae). Appl. Environ. Microbiol. 2015, 81, 3492-3501. [CrossRef] [PubMed]

43. Schiro, G.; Verch, G.; Grimm, V.; Müller, M.E.H. Alternaria and Fusarium Fungi: Differences in Distribution and Spore Deposition in a Topographically Heterogeneous Wheat Field. J. Fungi 2018, 4, 63. [CrossRef] [PubMed]

44. Belay, A.; Claassens, A.S.; Wehner, F.C.; de Beer, J.M. Influence of residual manure on selected nutrient elements and microbial composition of soil under long-term crop rotation. S. Afr. J. Plant Soil 2001, 18, 1-6. [CrossRef]

45. Wenda-Piesik, A.; Sun, Z.; Grey, W.E.; Weaver, D.K.; Morrill, W.L. Mycoses of wheat stem sawfly (Hymenoptera: Cephidae) larvae by Fusarium spp. Isolates. Environ. Entomol. 2009, 38, 387-394. [CrossRef]

46. Del Ponte, E.M.; Fellow, V.; Shah, D.A.; Bergstrom, G.C. Spatial Patterns of Fusarium Head Blight in New York Wheat Fields Suggest Role of Airborne Inoculum. Plant Health Prog. 2003, 4, 4. [CrossRef]

47. Paul, P.A.; El-Allaf, S.M.; Lipps, P.E.; Madden, L. V Rain Splash Dispersal of Gibberella zeae Within Wheat Canopies in Ohio. Phytopathology 2004, 94, 1342-1349. [CrossRef]

48. Hoffmann, A.; Funk, R.; Müller, M.E.H. Blowin' in the Wind: Wind Dispersal Ability of Phytopathogenic Fusarium in a Wind Tunnel Experiment. Atmosphere 2021, 12, 1653. [CrossRef]

49. Lozada-Gobilard, S.; Landivar Albis, C.M.; Rupik, K.B.; Pätzig, M.; Hausmann, S.; Tiedemann, R.; Joshi, J. Habitat quality and connectivity in kettle holes enhance bee diversity in agricultural landscapes. Agric. Ecosyst. Environ. 2021, 319, 107525. [CrossRef]

50. Braun-Blanquet, J. Pflanzensoziologie: Grundzüge der Vegetationskunde, 2nd ed.; Springer-Verlag: Wien, Austria, 1951. 